\title{
Eppur sí Muove: Mobilidade Humana, Cidadania e Globalização
}

Carolina Moulin*

Reza a lenda que, ameaçado de morte como decorrência de sua crença na visão heliocêntrica do mundo, contraposta ao modelo geocêntrico de uma Terra estacionária, defendido pela Igreja Católica, Galileu teria se retratado perante o Papado e suspirado, ao final, que "eppur si muove" (e, no entanto, ela - a Terra - se move). Se fato ou mito, a anedota é ilustrativa do tratamento dado ao estudo da mobilidade, em particular da mobilidade humana, na área de Relações Internacionais. O estudo do movimento era, até muito recentemente, percebido como prática quase herética para a disciplina. Centrada na tríade Estadoterritório-cidadão, e protegida pelo véu da soberania, a análise da política internacional centrava-se nos elementos de fixidez das dinâmicas políticas e percebia o movimento como ruptura problemática e como ocorrência patológica. O sistema seria marcado por condições estacionárias e por forças históricas contra as quais não se poderia lutar. A própria etimologia da palavra "Estado", o ator por excelência da política internacional, é indicativa da obsessão disciplinar com a constância. O termo Estado deriva do latim stare, verbo que indica permanecer ou manter-se de pé e do qual derivam outros termos, igualmente indicativos de inércia, como status. Não cabe aqui adentrar a crítica, já largamente discutida e contundentemente avançada no debate teórico,

* Ph.D. em Relações Internacionais pela McMaster University, Canadá, coordenadora da graduação e professora do Instituto de Relações Internacionais da Pontifícia Universidade Católica do Rio de Janeiro (IRI/PUC-Rio). E-mail: cmoulin@puc-rio.br. 
das vicissitudes da história e sociologia de uma disciplina construída a partir de e para um grupo restrito de países e tomadores de decisão. Cumpre salientar, contudo, que, a despeito de notáveis esforços e importantes contribuições, ${ }^{1}$ essa trajetória produziu uma cegueira relativa da área a um dos fenômenos mais resilientes, abrangentes e significativos da experiência humana: as migrações. ${ }^{2}$

De acordo com estimativa recente do Programa das Nações Unidas para o Desenvolvimento, uma em cada cinco pessoas no mundo se encontra em situação migratória. Dos mais de 1 bilhão de migrantes ao redor do globo, de diversos e muitas vezes precários status, 740 milhões circulam dentro de seus próprios países de origem, enquanto 200 milhões se movimentam internacionalmente (PNUD, 2009). Os dados, a despeito de sua precariedade estatística, mostram que a mobilidade humana é uma das principais forças das circulações globais no século XXI e responde por importantes reconfigurações sociais, políticas e econômicas da globalidade contemporânea. Afinal, migrar é parte constitutiva da experiência humana e do próprio processo de formação de grande parte das comunidades políticas que hoje chamamos de Estado.

Muito além de sua dimensão quantitativa, as migrações envolvem profundas transformações nas dinâmicas de vida individuais e coletivas. Enquanto fatos sociais, carregam consigo um elemento imensurável que é parte integral da negociação que se estabelece entre o "lugar de onde se vem" e o "lugar onde se está" (ANG, 2001). E, desse encontro, mutações sociopolíticas são engendradas, novas possibilidades abertas e, frequentemente, recrudescem-se medos e ódios provocados pela presença do estrangeiro, que se converte naquele que é "de fora" e ao mesmo tempo "estranho". Não surpreende, portanto, verificar que, no plano internacional, duas grandes chaves de compreensão da mobilidade humana parecem sobressair-se. Por um lado, alguns países e sociedades têm avançado uma leitura das migrações como fonte inesgotável e inescapável de temores e "problemas". Nessa linha, o imigrante é percebido como fonte de "desordens públicas" e como ameaça à homogeneidade social, econômica e cultural, árdua e violentamente buscada no processo histórico de confluência idealizada entre o Estado e a Nação 
(CEYHAN; TSOUKALA, 2002; ARENDT, 1986). Uma das consequências desse discurso tem sido a inclusão da temática migratória nas agendas de segurança nacional e internacional. Muros, barreiras, exigências crescentes de vistos e documentação, centros de detenção, militarização dos aeroportos e pontos de fronteira e um aparato de vigilância e controle do movimento humano são apenas a face mais visível de uma política securitizada para as migrações que parece ter se tornado, de um lado, cada vez mais global em extensão e, de outro, cada vez mais focada em certos grupos alvo (BIGO, 2002). Como salienta Bauman (1998), a mobilidade humana hoje se apresenta como uma das grandes chaves de produção e reprodução das desigualdades internacionais engendradas pelo processo de globalização. Para alguns, a circulação é acelerada e facilitada; o movimento é quase instantâneo, com vistos eletrônicos, fast passes, passaportes biométricos e modalidades de transporte eficientes em custo e tempo. Para outros, migrar é, se não impossível, extremamente arriscado: rotas subterrâneas, vidas e trajetórias invisíveis, recursos escassos e, quando acaso se chegue ao destino, uma miríade de incertezas e privações.

De outro lado, temos uma leitura mais positiva e otimista dos potenciais trazidos pelas migrações globais. No âmbito do discurso desenvolvimentista, o debate orienta-se para o impacto das remessas de recursos de imigrantes para seus países de origem e para a formação e circulação de trabalhadores migrantes qualificados. Outros, ainda, focam a migração do ponto de vista das sensibilidades culturais e políticas advindas de múltiplas e, por vezes, sobrepostas lealdades. Nessa esteira, o fenômeno migratório produz alterações constitutivas nos contornos da cidadania, agora transnacionalizada. Os imigrantes definem-se, para alguns, em termos de uma "cidadania latitudinal" que articula pertencimento jurídico ao país de origem, direitos de permanência no país de recepção, além de formas díspares nas condições legais e laborais entre novas geografias da produção (ONG, 2003, p. 282). Outros vão além, argumentando que os padrões correntes nos fluxos migratórios e as mudanças trazidas pela transversalidade de suas experiências 


\section{Carolina Moulin}

evidenciariam a emergência de uma ordem efetivamente cosmopolita (HELD, 2010).

A despeito da ampla e divergente gama de opiniões e debate sobre a dinâmica contemporânea da mobilidade humana, parece haver relativo consenso sobre a sua absoluta relevância para o cenário político internacional. Mais do que isso, parece-nos que as migrações articulam mudanças cruciais sobre o panorama social, político, econômico e cultural em que vivemos, produzindo assim importantes rearticulações nas formas pelas quais se governam pessoas e, fundamentalmente, nas definições sobre quem e sobre onde se deve dar esse controle. Nesse sentido, não se deve superestimar a possível contribuição do campo de Relações Internacionais para o estudo da mobilidade humana. A complexidade, mutabilidade e multidimensionalidade da questão migratória demandam similar mobilidade por meio de e entre fronteiras disciplinares. É esse o espírito do número que ora se apresenta ao leitor. As contribuições aqui selecionadas fazem parte de um diálogo promovido pelo Instituto de Relações Internacionais da Pontifícia Universidade Católica do Rio de Janeiro (IRI/PUC-Rio), com apoio da Fundação Carlos Chagas Filho de Amparo à Pesquisa do Estado do Rio de Janeiro (FAPERJ) e da Coordenação de Aperfeiçoamento de Pessoal de Nível Superior (CAPES), realizado em outubro de 2010. O Colóquio Internacional "Mobilidade Humana e Cidadania: Migrações, Refúgio e Globalização" discutiu os desafios apresentados às noções tradicionais de cidadania e à política internacional contemporânea pela experiência da mobilidade humana no mundo globalizado. Apresentou uma abordagem multidisciplinar sobre os impactos e consequências do fenômeno migratório sobre uma gama de importantes aspectos das reconfigurações políticas atuais, tanto locais quanto globais. O resultado desse debate, aqui apresentado, reflete os diferentes olhares e perspectivas daqueles que, a despeito de suas próprias e diversas trajetórias e investimentos de pesquisa, permitem-nos, ao fim e ao cabo, refletir melhor e de forma mais holística sobre as inflexões que a questão migratória traz para o Brasil e para o mundo.

Longe de constituir um todo coeso, este número reflete a própria natureza multifacetada dos processos migratórios e, nesse sentido, escapa 
a qualquer organização reducionista. Apesar disso, proponho ao leitor encarar a jornada proposta a partir de três grandes perspectivas ou olhares que iluminam, com suas restrições e potenciais, a compreensão sobre as migrações contemporâneas. A primeira linha articula análises que discutem os processos normativos e institucionais que nos ajudam a conformar o panorama migratório, tanto regional quanto globalmente. Elspeth Guild demonstra como a dinâmica de conformação da União Europeia possui uma relação direta com a questão migratória, por meio da análise das transformações legislativas no âmbito suprarregional, indicando as tensões derivadas da extensão do direito de mobilidade aos cidadãos intracomunitários e as restrições impostas aos não europeus. Rossana Rocha Reis, por seu turno, demonstra como a política brasileira para as migrações se transformou, diante das mudanças na agenda multilateral internacional e dos próprios contornos da agenda de política externa brasileira, notadamente vinculando a temática aos dilemas mais amplos do processo de redemocratização e de uma política orientada pelos ditames dos direitos humanos. Luis E. Aragón analisa os censos demográficos para construir um panorama das migrações na Pan-Amazônia, demonstrando as especificidades dos deslocamentos humanos em uma região marcada por dificuldades na sua delimitação territorial e pelo entroncamento de povos, culturas e nacionalidades.

A segunda linha não só avança leituras calcadas em experiências específicas acerca das migrações, como também salienta a relevância dos aspectos socialmente construídos para a integração, recepção e exclusão de grupos de imigrantes nas sociedades de acolhida. Vicki Squire produz uma análise crítica dos limites da cidadania europeia, por meio de uma investigação minuciosa e lúcida sobre a situação dos roma no continente. As recorrentes políticas de controle, criminalização e reclusão desse grupo minoritário e por natureza nômade colocam em xeque os postulados basilares do projeto europeu, calcado historicamente na liberdade de movimento e na proteção dos direitos humanos. Dentro da experiência sul-americana, Sylvain Souchaud demonstra como se constituíram, historicamente, as representações sobre a dinâmica migratória entre Brasil e Paraguai. O autor mostra como a percepção brasileira do 
Paraguai (e, por conseguinte, dos paraguaios) como país fechado, violento e marcado pelo "ilícito e pelo falsificado" acaba se refletindo nos modos pelos quais são (des)incorporados na comunidade hospedeira. Imagens e representações são, nesse sentido, fundamentais para a compreensão dos processos de inclusão e exclusão que pautam o cotidiano de comunidades migrantes. Essas ressignificações também fazem parte do próprio imaginário dos imigrantes que trazem consigo expectativas, esperanças e sonhos, muitas vezes recosturados no contato com as novas comunidades de residência. Sidney Antonio da Silva analisa como esses processos de renegociação se dão entre os hispano-americanos no Amazonas, focando particularmente a construção dos estigmas sociais e as dinâmicas de gênero.

$\mathrm{Na}$ esteira dessa crítica, temos a terceira linha de contribuições, que, em certa medida, abarca, ainda que subliminarmente, grande parte das análises propostas. Trata-se aqui da reflexão sobre as consequências humanas dos processos de regulação, controle e incorporação das migrações no debate teórico e político atual. Por um lado, temos as limitações conceituais e de abordagem que acabam por dificultar a compreensão do fenômeno migratório como "fato social total" (MAUSS, 1974). Claudia Aradau, Jef Huysmans e Vicki Squire procuram indicar uma possível saída para esse paradoxo, calcando-se na ideia de "atos de cidadania", originalmente desenvolvida por Isin e Nielsen (2008). Essa sociologia política da mobilidade implica uma redefinição da própria cidadania, menos como estatuto jurídico e mais como prática social e política. Se assim for, a luta dos imigrantes por direito e justiça seria indicativa do exercício de uma cidadania não mais sequestrada pelos requisitos da nacionalidade, tampouco pelos ditames da governamentalidade da mobilidade. Referida leitura envolve, portanto, um olhar atento para as dinâmicas correntes de contestação e organização de grupos migrantes dos mais diferentes matizes, para suas agendas e demandas e para os dilemas e tensões que produzem nas formas tradicionais de pensar e agir políticos. Refletindo sobre a experiência norte-americana, Roxanne Lynn Doty articula uma contundente releitura do lugar da morte e de sua importância para a reflexão sobre a dinâmica da mobilidade contemporânea. Estabelece uma 
crítica feroz à banalidade da crueldade que hoje parece pautar a política imigratória nos EUA (e talvez em grande parte dos países desenvolvidos). Repensando o papel do testemunho, do trauma e da própria morte, Doty elucida a conversão da ausência desses sujeitos, que pereceram nos percursos insalubres das rotas migratórias, em uma presença política importante para a mobilização e questionamento das estruturas de gerenciamento e controle das fronteiras. Essas demandas se dão também no interstício das vidas daqueles que, no deslocamento, foram violentamente sugados pelas condições inóspitas à mobilidade em certas partes do mundo. Finalmente, Leticia Calderón Chelius, embora a partir de quadro teórico distinto, avança uma substantiva análise de como a disputa por direitos políticos de comunidades emigradas amplia os horizontes de possibilidade e realização de uma cidadania transnacional, que se implementa, de fato, em função da organização e das demandas de grupos emigrados em diferentes países latino-americanos.

Assim, longe de prover um quadro estático e geral para aquele que se debruça sobre a temática da mobilidade humana, os diferentes autores nos convidam, sobretudo, a problematizar a percepção que, cotidiana e corriqueiramente, temos assimilado sobre as migrações e seus sujeitos. Trata-se de um número especial não só pelo tema que percorre os diferentes caminhos analíticos e espaços de investigação apresentados, mas também pela reflexão sistemática proposta, que promove e abraça a complexidade das experiências humanas, sempre móveis e voláteis, do mundo em que vivemos.

\section{Notas}

1 Os trabalhos dos teóricos críticos e de influência marxista são importantes exceções na paisagem árida dos estudos migratórios em Relações Internacionais até meados da década de 1980. Esses autores enfatizavam o caráter transnacional das migrações, por um lado, e a dinâmica estruturante da circulação da mão de obra perante a internacionalização das estruturas produtivas capitalistas, por outro, 


\section{Carolina Moulin}

ressaltando a natureza constitutiva da mobilidade dos fatores de produção na formação e reprodução do sistema-mundo ou das ordens mundiais. Martin O. Heisler e Barbara Schmitter Heisler (1986) talvez tenham sido os primeiros a produzir um trabalho especificamente dedicado ao tema das migrações a partir dos debates específicos da área de Relações Internacionais, focando aspecto que seria crucial para as contribuições mais recentes sobre o tema, qual seja a vinculação entre mobilidade humana e transnacionalismo. Releve-se que esses autores adentram o campo disciplinar na esteira das contribuições que viriam a relativizar o papel do Estado, sobretudo a partir de meados da década de 1970.

2 O termo "migrações", como usado ao longo do texto, refere-se tanto ao imigrar (i.e., entrar em uma sociedade/grupo/país de que não se é originário) quanto emigrar (i.e., sair de sociedade/grupo/país do qual se é originário). Tampouco, e propositalmente, distingue-se aqui entre imigrante e migrante, nem entre diferentes "categorias" de imigrantes (como imigrantes voluntários e forçados, econômicos e refugiados, regulares e irregulares), pois referidas adjetivações falam menos da natureza e dinâmica do ato de migrar do que das formas pelas quais se gerencia e controla o movimento das pessoas. Essa economia discursiva é fundamental para a compreensão da política internacional da mobilidade, mas escapa aos propósitos introdutórios que essa contribuição visa atender. Sobre essa questão, ver Moulin (no prelo).

\section{Referências} Bibliográficas

ANG, Ien. On not speaking Chinese: living between Asia and the West. Nova Iorque: Routledge, 2001.

ARENDT, Hannah. The origins of totalitarianism. Nova Iorque: Harvest Book, 1986.

BAUMAN, Zygmunt. Globalization: the human consequences. Nova Iorque: Columbia University Press, 1998. 


\section{Eppur si Muove: Mobilidade Humana, Cidadania \\ e Globalização}

BIGO, D. Security and immigration: toward a critique of the governmentality of unease. Alternatives: Global, Local, Political, v. 27, n. suplementar, p. 63-92, 2002.

CEYHAN, A.; TSOUKALA, A. The securitization of immigration in Western societies: ambivalent discourses and policies. Alternatives: Global, Local, Political, v. 27, n. suplementar, p. 21-39, 2002.

HEISLER, Martin O; HEISLER, Barbara Schmitter. Transnational migration and the modern democratic State: familiar problems in new form or a new problem? Annals of the American Academy of Political and Social Science, v. 485, p. 12-22, 1986.

HELD, David. Cosmopolitanism: ideals and reality. Cambridge: Polity Press, 2010 .

ISIN, Engin; NIELSEN, G. Acts of citizenship. Londres: Zed Books, 2008.

MAUSS, Marcel. Ensaio sobre a dádiva, forma e razão da troca nas sociedades arcaicas. In: . Sociologia e antropologia. v. 2. São Paulo: EPU/EdUSP, 1974.

MOULIN, Carolina. A política internacional da mobilidade. In: SILVA, S. A. da. (Ed.). Migrações na Pan-Amazônia. Manaus: Editora da UFAM, [no prelo].

ONG, Aihwa. Buddha is hiding: refugees, citizenship, the new America. Berkeley: University of California Press, 2003.

PNUD - Programa das Nações Unidas para o Desenvolvimento. Human development report - overcoming barriers: human mobility and development. 2009. Disponível em: <http://hdr.undp.org/en/media/HDR_2009_PT_Complete.pdf $>$. Acesso em: 10 jul. 2010. 